\title{
TIPOS DE COLÁGENO NA FIBROSE HEPÁTICA ESQUISTOSSOMÓTICA DE SYMMERS
}

\author{
Pedro Raso, Nivaldo Hartung Toppa, Dionne M. Oliveira e Francira P. Lemos
}

Os $A A$, estudaram o tipo de colágeno em cortes histológicos de fragmentos de fígado de 12 individuos portadores da forma hepatesplênica da esquistossomose mansoni, pela técnica de coloração pelo Sirius Supra Red F3BA. Como controle usaram cortes histológicos de 12 fragmentos de figado de individuos sem doenças fibrosantes. As preparaçōes coradas pelo Sïrius Supra Red F3BA e examinadas em microscópio de polarizaçâo (Leitz) revelaram que a fibrose periportal é constituida por colágeno de tipos I e III, com predominância do primeiro.

Palavras chaves: Schistosoma mansoni. Forma hepatesplênica. Tipo de colágeno. Picrosirius-polarização.

A forma hepatesplênica descrita inicialmente por Symmers (1904), foi bem estudada por vários autores. Entre esses destacam-se os achados de Bogliolo, que em trabalhos sucessivos ${ }^{3} 567$ teve o mérito de estabelecer, com segurança, não somente as bases anatômicas dessa forma, mas também, de separá-la definitivamente do grupo das cirroses. Por esta razão achamos justo chamá-la de forma de Symmers-Bogliolo.

A principal característica anatômica da esquistossomose hepatesplênica consiste em uma neoformação conjuntiva, sistematizada, restrita aos espaços portais, sem tendência a invadir e a subverter a arquitetura lobular. A gênese da fibrose continua ainda no terreno das hipóteses.

Pelas técnicas imunocitoquímicas e bioquímicas demonstrou-se, no fígado normal, a existência de colágeno de tipos I, III, IV e B. Apesar do tipo I ter sido identificado apenas nos espaços portais ${ }^{2}$, observou-se reação a anticorpos ao colágeno deste tipo ao longo da parede dos sinusóides ${ }^{12}$. 0 tipo III foi identificado nos vasos, nos espaços perissinusoidais e nos tratos portais ${ }^{2} 812$ e do tipo IV nos espaços perissinusoidais, vasos sangüíneos e

\footnotetext{
Trabalho dos Departamentos de Anatomia Patológica e Medicina Legal da Faculdade de Medićina da Universidade Federal de Minas Gerais e de Biologia do Instituto de Ciências Exatas e Biológicas da Universidade Federal de Ouro Preto, executado com recursos do CNPq e FINEP. Endereço para correspondência: Pedro Raso, Av. Alfredo Balena 190, Faculdade de Medicina da UFMG, Departamento de Anatomia Patológica e Medicina Legal. 30.000. Belo Horizonte-MG.

Recebido para publicação em 4/7/1983.
}

linfáticos, ductos e dúctulos biliares e ao redor dos axônios.

Segundo nos consta, apenas Biempica e cols $(1983)^{2}$ determinaram por meios imunocitoquímicos os tipos de colágeno presentes na forma hepatesplênica da esquistossomose mansoni. Estudando biópsias de oito pacientes (quatro portadores somente de esquistossomose, dois com esquistossomose e hepatite crônica ativa, e dois de hepatite crônica ativa com $\mathrm{HbsAg}$ positivo) selecionados para esplenectomia no Egito, demonstraram em todos eles, depósitos de colágeno dos tipos I, III e B nos septos fibrosos do fígado.

Esta pesquisa tem por finalidade identificar os tipos de colágeno na forma de Symmers-Bogliolo da esquistossomose mansoni pelo método de picrosirius polarização ${ }^{10}$.

\section{MATERIAL E METODOS}

O material consta de fragmentos de fígado de 12 indivíduos portadores da forma de Sym. mers-Bogliolo autopsiados no Departamento de Anatomia Patológica e Medicina Legal da UFMG. De cada caso os fragmentos foram retirados em áreas não subcapsulares, fixados em solução de formol a $10 \%$ e incluídos em parafina. Os cortes de 4 a 5 micrômetros foram corados pela hematoxilina-eosina, tricrômico de Gomori e pelo Sirius Supra Red F3BA (distribuído por Verona Dyestuffs, PO box 385, Springfield Road, Union, New Jersey). Como controle utilizamos cortes histologicos de fígado de 12 indivíduos sem doenças fibrosantes. 
Raso P, Toppa NH, Oliveira DM, Lemos FP. Tüpos de colágeno na fibrose hepática esquistossomática de Symmers. Revista da Sociedade Brasileira de Medicina Tropical 16:202-205, Out-Dez, 1983

As preparaçð̄es obtidas foram examinadas em microscópio óptico (Zeiss), e as preparaçōes coradas pelo Sirius Supra Red F3BA no microscópio de polarização (Leitz) conjugado a máquina fotográfica.

\section{RESULTADOS}

Os cortes histológicos nos doze casos da forma hepatesplênica apresentavam as caracteristicas da forma de Symmers-Bogliolo. Em sua essência, consistiam numa neoformação conjuntiva estritamente portal, sem tendência a invadir e a subverter a arquitetura lobular, embora, nos casos mais avançados, a proliferação atingisse, também, os espaços sublobulares provocando uma certa septação do órgão.

Examinados à luz polarizada mostraram um nítido contraste entre o conjuntivo intra e extra lobular. O primeiro era constituído por delgadas fibrilas, uniformes, predominantemente esverdeadas (tipo III) que se interpunham entre os sinusóides e as lâminas de hepatócitos. Excepcionalmente, em um caso ou outro e geralmente na forma grave e avançada da doença, foram observados focos intralobulares de condensação de fibras. Isto ocorreu em zonas onde o sofrimento do hepatócito foi maior em conseqüência, com toda possibilidade, do distúrbio da circulação provocado pela doença. Nestas zonas, formou-se colágeno amarelo-alaranjado (tipo I) que se misturava com o colágeno esverdeado (tipo III) sob a forma de fibrilas mais espessas, curtas, irregulares e sinuosas, interpretadas como resultantes do colápso. Repetimos que este achado foi excepcional. Pelo contrário, nos espaços porta, onde ocorrem as lesões principais e características dessa forma de doença, o conjuntivo adquiriu aspectos peculiares. Nas formas antigas, onde era nítida a desproporção entre a fibrose e os ovos ou granulomas (estes últimos raramente presentes), notou-se que a fibrose era constituída por fibras do tipo I e III, mescladas entre si, mas com nítida predominância das primeiras. Estas apareciam com fibrilas delgadas ou às vezes mais espessas, sinuosas, longas ou curtas, paralelas ou não entre si, com freqüência seguindo várias direçð̃es; formavam um todo, mais ou menos uniforme, mas, freqüentemente, tendiam a se tornar mais espessas na região próxima do lóbulo, e mais frouxas e mais delgadas em torno dos ramos venosos e arteriais.

Por outro lado, nos casos graves de fibrose mas acompanhados de um grande número de ovos e granulomas, notava-se um comportamento diferente do colágeno neoformado. Distinguiam-se, nitidamente, duas zonas ditadas pela presença uu não de granulomas. Nas zonas adjacentes aos lóbulos, onde não havia granulomas, o colágeno era predominantemente do tipo $\mathrm{I}$. Suas fibras eram mais longas, mais espessas, mais compactas e tendiam a formar estruturas mais ou menos paralelas entre si (Fig. 1). Nas áreas correspondentes às sedes dos granulomas, a coloração era muito mais fraca e tendia para o verde. Isto porque era muito menor o número de fibrilas, pois estas eram relativamente escassas nos locais de inflamação. Em outras palavras, eram praticamente inexistentes nos granulomas. Como conseqüência, as fibrilas do tipo I e III, ora com predomínio de uma ou de outra, seguiam um curso irregular. Na maioria das vezes eram mais delgadas, sinuosas e fragmentadas (Fig. 1). Em alguns casos onde a fibrose periportal era muito intensa, observava-se a formação de traves conjuntivas perpendiculares, não muito espessas, que partindo do conjuntivo justalobular, penetravam entre os lóbulos, septando-os parcialmente, mas nunca insulando-os. Estes eram constituidos por fibras tipo I e III, com predomínio das primeiras e formavam traves mais ou menos longas, irregulares, que se exauriam a uma distância mais ou menos longa do espaço porta correspondente (Fig. 2).

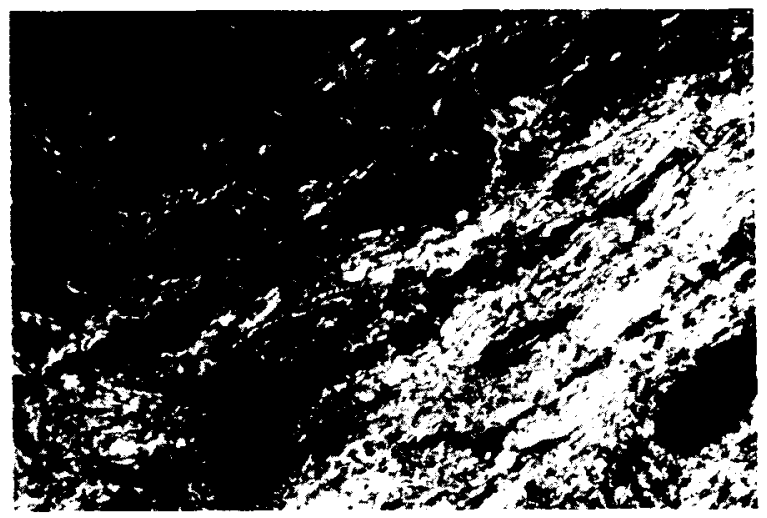

Figura 1 - Espaço porta. A metade inferior da figura revela fibras colágenas do tipo I (amarelas e bem refringentes). A metade superior, pobre em fibras colágenas, porém com predomínio de fibras do tipo III (esverdeadas), correspondente a área com numerosos granulomas esquistossomóticos, cujos espaços negros são os deixados pelos ovos do $S$. mansoni (Picrosirius-Polarização x 60).

Os ramos arteriais e venosos existentes nos espaços porta mostravam na adventícia colágeno do tipo I preponderante que continuava com o conjuntivo neoformado. Os capilares neoformados 
Raso P, Toppa NH, Oliveira DM, Lemos FP. Tipos de colágeno na fibrose hepática esquistossomática de Symmers. Revista da Sociedade Brasileira de Medicina Tropical 16:202-205, Out-Dez, 1983

davam imagens lacunares, de tamanhos diversos, proporcional à difração da luz, envolvidos por conjuntivo. Nos nervos preponderava o conjuntivo tipo III e por esta razão tendiam tomar uma colo. ração esverdeada.

No grupo controle o aspecto do conjuntivo intralobular era praticamente idêntico ao do grupo da esquistossomose; o conjuntivo periportal, entretanto, era mais frouxo, em menor quantidade e a preponderância das fibras de tipo I sobre as do tipo III era muito menos evidente.

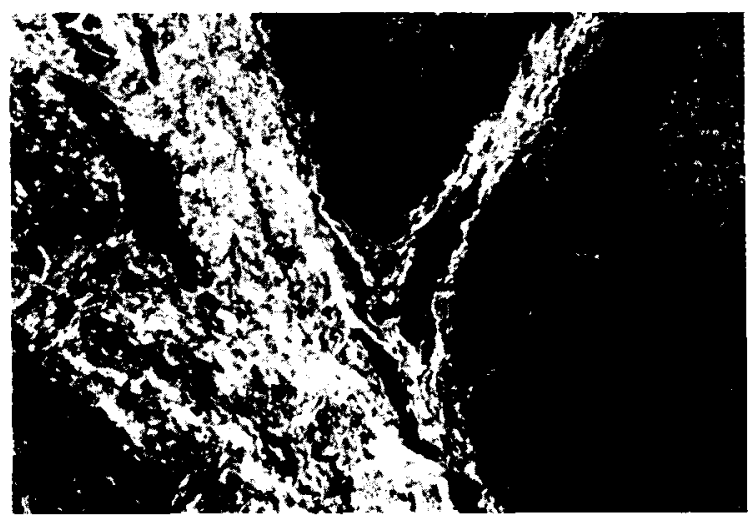

Figura 2 - Espaço porta. Mostra nítido predomínio das fibras colágenas do tipo I (amarelas) sobre as do tipo III (esverdeadas), que penetram no lóbulo hepático septando-o parcialmente. (Pricrosírius-polarização x 60).

\section{DISCUSSÃO}

Pelo que nos consta, até o momento. 0 único estudo no sentido de determinar os tipos de colágeno na forma hepatesplênica foi o de Biempica e $\mathrm{cols}^{2}$ que, por métodos imunocitoquímicos, verificaram o aumento dos tipos I, III e B. Na cirrose há aumento dos tipos I e III. ${ }^{8} 1214 \quad 15$

Usando técnica simples de coloração preconizada por Junqueira e cols ${ }^{1011}$ (picrosirius polarização) confirmamos o aumento do colágeno I e III, principalmente do primeiro, nos espaços portais na forma hepatesplênica da esquistossomose mansoni.

O tipo I, mais abundante, formado por fibras mais longas, mais espessas, às vezes paralelas, especialmente na região mais próxima da periferia dos lóbulos e mais distantes dos granulcmas, parece ser o responsável pela hipertensão portal na esquistossomose. Como o conjuntivu neoformado é idêntico ao encontrado normalmente nos espaços porta (tipos I e III), pode-se afirmar, com certa segurança, que os estímulos responsáveis pela fibrose não provocavam desvios qualitativos de função dos fibroblastos. É provável que, em conseqüência da inflamação, o fibroblasto passe a sintetizar e a exportar mais colágeno na unidade de tempo. O desvio, portanto, seria apenas quantitativo . Em outras palavras, os fibroblastos são estimulados a produzir e excretar mais colágeno idêntico ao encontrado no fígado normal. Todavia, os fatores responsáveis por este estímulo não foram elucidados.

Foge dos objetivos deste trabalho a análise sobre a patogênese da fibrose cujos mecanismos continuam no terreno das hipóteses.

\section{SUMMARY}

Histologic typing of collagen fibers from 12 livers of patients with hepatosplenic Manson's schistosomiasis was made using the Sirius Supra Red F3BA stain according to Junqueira's method. The controls were 12 livers without fibrosis. The preparations were stained with Sirius Supra Red F3BA and were examined under polarized light (Leitz photomicroscope) which revealed collagen fibers types I and III in the portal tracts.

Key words: Manson's schistosomiasis. Hepatesplenic form. Collagen type. Picrosirius-polarization.

\section{REFERÊNCIAS BIBLIOGRÄFICAS}

1. Biempica L, Morecki R, Wu CH, Giambrone MA, Rojkind $M$. Immunocy tochemical localization of type B collagen: A component of basement membrane in human liver.' American Journal of Pathology. $98: 591-620,1980$.

2. Biempica L, Dunn MA, Kamel TA, Kamel R, Hait PK, Fleischner C, Biempica SL, Wu CH, Rodjkind M. Liver collagen-type characterization in human scnistosomiasis. A histological, ultrastructural, and immunocy tochemical correlation. American Journal of Tropical Medicine and Hygiene 32:316-325, 1983.

3. Bogliolo L. Sobre o quadro anatômico do fígado na esquistossomose mansônica hépato-esplênica. O Hospital 45:283-306, 1954.

4. Bogliolo L. Segunda contribuição ao conhecimento do quadro anatômico do fígado na esquistossomose mansônica hépato-esplênica. O Hospital 47:507542,1955 
Raso P, Toppa NH, Oliveira DM, Lemos FP. Tipos de coldgeno na fibrose hepática esquistossomática de Symmers. Revista da Sociedade Brasileira de Medicina Tropical 16:202-205, Out-Dez, 1983

5. Bogliolo L., The anatomical picture of the liver in hepato-splenic schistosomiasis mansoni. Annals of Tropical Medicine and Parasitology' 51:1-14, 1957.

6. Bogliolo L. Quinta contribuição ao estudo da esquistossomose mansônica hépato-esplênica. Análise das teorias patogenéticas da lesão hepática, com especial referência à forma de Symmers. O Hospital 52: 271-306, 1957.

7. Bogliolo L. Subsídios para o conhecimento da forma hépato-esṕlênica e/ou forma toxêmica da esquistossomose mansônica. Rio de Janeiro, Serviço Nacional de Educação Sanitária, 301 p., 1958.

8. Gay S, Fietzek PP, Remberger K, Künn K. Liver cirrhosis: Immunofluorescence and biochemical studies demonstrate two types of collagen. Klinische Wochenschrift 53:205-208, 1975.

9. Hahn E, Wich G, Pencer D, Timpl R.Distribution of basement membrane proteins in nofmal and fibrotic human liver: collagen type IV, laminin and fibronectin. Gut, 21:63-71, 1980.

10. Junqueira LCU, Cossermelli W, Brentani R. Differential staining of collagen types I, II and III by Sirius Red and polarization microscopy. Archives of
Histology Japanese 41:267-274, 1978.

11. Junqueira LCU, Bignolas G.Brentani RR. Picrosirius staining plus polarization microscopy, a specific method for collagen detection in tissue sections. Histochemical Journal 11:447-455, 1979.

12. Ott U, Hahn E, Moshudis E, Bod JC, Marini GA. Immunohistogischer wachweis von typ I und typ IIIKollagen in lieberbiopsien: früne und spate veranderungen bei alkoholischer lebererkrankung. Verhandlungen der Deutschen Gesellschaft für Innere Medizin 83:537-540, 1977.

13. Popper H, Piez KA. 'Collagen metabolism in the liver. American Journal bf Digestive Disease 23:641-658, 1978.

14. Remberg K, Gay S, Fietzek PP.Immunohistochemische untersucungen zur kollagencharakterisienung in liebercirrhosen. Virchows Archives (Pathol Anat) 367:231-240, 1975.

15. Rojkind $\mathbf{M}$, Martinez-Palomo $\mathbf{A}$. Increase in type $\mathbf{I}$ and type III collagens in human alcoholic liver cirmosis. Proceedings of National Academy of Sciences USA 73:539-543, 1976. 